\title{
Correction: Assessing minimal medical statistical literacy using the Quick Risk Test: a prospective observational study in Germany
}

Jenny MA, Keller N, Gigerenzer G. Assessing minimal medical statistical literacy using the Quick Risk Test: a prospective observational study in Germany. BMJ Open 2018;8:e020847. doi: 10.1136/bmjopen-2017-020847.

The previous version of this manuscript contains an error in table 1:

In question 4, option D "Sensitivity" should be change into "Specificity"

Question
1. A test's sensitivity is a central criterion for its quality as a diagnostic tool.
The sensitivity is
2. A test's specificity is a central criterion for its quality as a diagnostic tool.
The specificity is

The specificity is

\section{Possible answers}

A) the proportion of people with a positive test result among those who are sick. ${ }^{* \star *}$

B) the proportion of people with a negative test result among those who are sick.

C) the proportion of people with a positive test result among those who are healthy.

D) the proportion of people with a negative test result among those who are healthy.

A) the proportion of people with a positive test result among those who are sick.

B) the proportion of people with a negative test result among those who are sick.

C) the proportion of people with a positive test result among those who are healthy.

D) the proportion of people with a negative test result among those who are

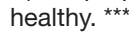

3. Which test characteristic quantifies the probability that a person with a positive test result actually has the disease?

4. Which test characteristic quantifies the probability that a person with a negative test result does not have the disease?

5. A medical test's manufacturer tells you the sensitivity and the specificity of its test. You would like to tell your patient the probability that they are sick if they have a positive test result. Which measurement do you need for your calculation?

6. Mammography is often used as a screening-test to detect breast cancer early. The probability that a woman has breast cancer is $1 \%$. When a woman has breast cancer her probability of receiving a positive mammogram is $90 \%$ When a woman does not have breast cancer her probability of nevertheless receiving a positive mammogram is $9 \%$. What is the best estimate for the number of women with a positive screening mammogram who actually have breast cancer?

7. In a medical publication you read that screening with mammography lowers the probability of dying from breast cancer by $20 \%$. This number is

8. A patient asks you about the benefits of cancer screening. Which criterion should you consider here?

\begin{abstract}
9. Imagine two groups of people who all die of cancer at age 70 . In group A cancer is detected via screening at the age of 60 . In this group, the 5-year survival rate is $100 \%$. Group B is not screened. In this group, cancer is detected at age 68. Everyone dies at age 70 . Thus, the 5 -year survival rate is $0 \%$. Which bias explains why both groups have different 5 -year survival rates?
\end{abstract}

10. A higher screening rate results in more positive diagnoses. In screening, if anomalies are discovered, which because of their extremely slow growth would never cause symptoms or an early death, this is called
A) Positive predictive value ${ }^{\star \star \star}$

B) Negative predictive value

C) Specificity

D) Sensitivity

A) Sensitivity

B) Positive predictive value

C) Negative predictive value ${ }^{* * \star}$

D) Specificity

A) Mortality

B) Prevalence **

C) Coherence

D) Latency

A) 9 in 10

B) 8 in 10

C) 1 in $10^{\star \star \star}$
D) 1 in 100

C) 1 in $10^{*}$

A) a relative risk reduction. ${ }^{* *}$

B) an absolute risk reduction.

C) a specific risk reduction.

D) an evident risk reduction.

A) 5-year survival rate

B) Incidence

C) Mortality rate ***

D) Prevalence

\section{A) Selection bias}

B) Overdiagnosis bias

C) Lead-time bias ***

D) Performance bias 
Open access This is an open access article distributed in accordance with the Creative Commons Attribution Non Commercial (CC BY-NC 4.0) license, which permits others to distribute, remix, adapt, build upon this work non-commercially, and license their derivative works on different terms, provided the original work is properly cited, appropriate credit is given, any changes made indicated, and the use is non-commercial. See: http://creativecommons.org/licenses/by-nc/4.0/.

(c) Author(s) (or their employer(s)) 2018. Re-use permitted under CC BY-NC. No commercial re-use. See rights and permissions. Published by BMJ.

BMJ Open 2018;8:e020847corr2. doi:10.1136/bmjopen-2017-020847corr2

(A) Check for updates 